\title{
7 \\ THE \\ Field-Scale Measurement of Groundwater Profiles in a Drained Slope
}

GEOLOGICAL

SOCIETY

OF AMERICA ${ }^{\circledR}$

DIANA I. COOK

PAUL M. SANTI

JERRY D. HIGGINS

Department of Geology and Geological Engineering, Colorado School of Mines, 1516 Illinois Street, Golden, CO 80401

RICHARD D. SHORT

Blackhawk Geologic Hazard Abatement District, 4125 Blackhawk Plaza Circle, Danville, CA 94506

Key Terms: Groundwater, Slope-Stability, Horizontal, Drains, Field-Measurement

\section{ABSTRACT}

In 2003, Crenshaw and Santi developed a method for calculating average piezometric heads between horizontal drains in a slope. The method relies on drain flow rates, slope geometry, and soil hydraulic conductivity. The corrugated shape of groundwater profiles between drains and the departure of the groundwater surface from the drain near its uphill end were verified using laboratory-scale physical and computer modeling. In 2007, a study was conducted seeking to confirm these findings using field-scale modeling. The test site consists of a $2 \mathrm{H}: 1 \mathrm{~V}$ ( 2 horizontal : 1 vertical), $30 \times 12 \mathrm{ft}$ $(9.1 \times 3.7 \mathrm{~m})$ concrete slope representing low-permeability bedrock. Five perforated pipes embedded in the concrete are used to simulate base-flow recharge. The concrete was covered with a lean clay, and two wick drains were installed at a spacing of $8 \mathrm{ft}(2.4 \mathrm{~m})$. Fifty standpipe piezometers were installed to measure groundwater profiles between and along drains. Measurements were taken during recharge and drawdown events. The test was repeated with a clayey sand. Test results generally confirm the findings of Crenshaw and Santi, with some localized variations in groundwater profiles. The variations are most likely due to factors such as heterogeneous soil properties, the development of preferential pathways, boundary effects, etc. Fieldtesting also yielded additional information about the behavior of drained slopes that may be useful for future slope-stability projects. As a result of this research, recommendations for using Crenshaw and Santi's method to estimate piezometric heads between short, high-angle sub-horizontal drains in shallow landslides for use in slope-stability analyses are provided.

\section{INTRODUCTION}

Landslides, debris flows, and mudflows are common geologic hazards throughout the world. One of the most common preventative and remedial techniques used to reduce the likelihood and magnitude of the occurrence of these hazards is groundwater drainage. However, design and installation of horizontal drains is still based very much on experience, observation, and local practice and not on standardized engineering techniques (Cook et al., in press).

This article specifically addresses a common assumption in slope-stability modeling, namely, that the groundwater profile stays fairly level across the slope; that is, perpendicular to the slope angle. Laboratory-scale physical modeling and computer modeling have shown that this is not the case when horizontal drains have been installed. The groundwater is lowest at the drain location and rises between drains (Figure 1). Accounting for the remedial drainage effect on a three-dimensional (3-D) groundwater profile in a slope-stability model can make a difference in the safety factor by as much as 10 percent (Santi et al., 2003). A potential method exists for estimating the drainage effect on piezometric heads within remedially-engineered slopes for use in stability analyses (Crenshaw, 2003; Crenshaw and Santi, 2004), but was not previously verified with field-scale testing.

In an effort to verify this potential method for estimating groundwater levels in drained slopes, two soil slopes were constructed at the Blackhawk Geologic Hazard Abatement District (GHAD) test site near Danville, California, during the summer months of May, June, and July in 2007. The two slopes, a sandy clay (CL) slope and a clayey sand (SC) slope, built consecutively, were each outfitted with 


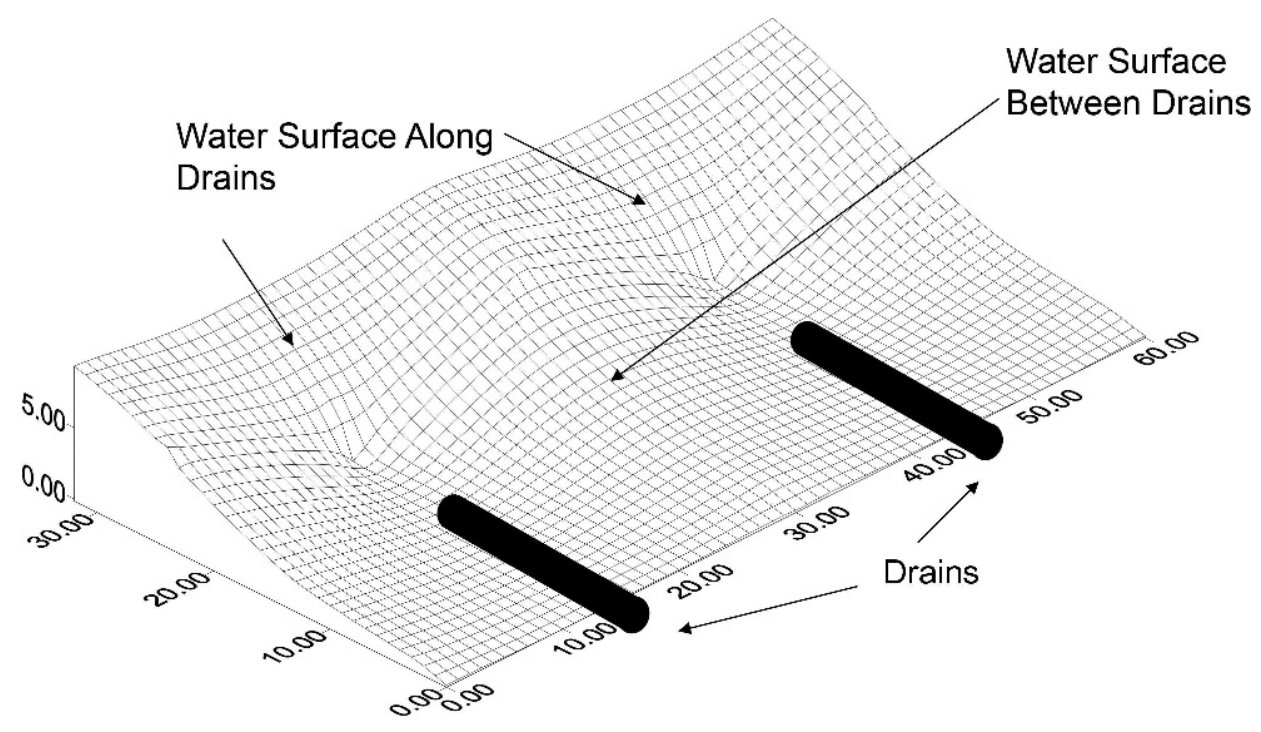

Figure 1. Shape of groundwater surface within a drain field. Note troughs corresponding to drain locations and ridges located between drains (Crenshaw and Santi, 2004).

two horizontal wick drains and 50 piezometers and were built above perforated water pipes used to simulate recharge. The materials and geometry used in the construction of the slopes were estimated to be representative of shallow landslides common to the GHAD and to other hill-slope areas in California, which are characterized by homogenous to semihomogeneous soils or weak-rock slope materials that are largely unaffected by the presence of rock joints. The constructed slopes were used to observe the effects of recharge and drainage on groundwater profiles within shallow soil slopes to improve the design and installation of slope-drainage projects. The purpose of this article is to document the testing program and provide a comparison of field-measured groundwater levels and profile shapes with those predicted using Crenshaw and Santi's method. In addition, the article provides recommendations for using the method to estimate piezometric heads between short, high-angle (20-25 degree inclinations from the horizontal) sub-horizontal drains in shallow landslides for use in slope-stability analyses.

\section{BACKGROUND}

In general, Crenshaw and Santi's (Crenshaw, 2003; Crenshaw and Santi, 2004) work showed the groundwater surface in a drained slope to be corrugated in shape, with lows along the drains and highs between them (Figure 1). In the upper part of the slope, along the back half of the drains, the groundwater surface diverges from the drains, rising above them (Figure 2). Crenshaw and Santi's work also established a method for averaging a 3-D groundwater surface to create a representative two-dimensional (2-D) groundwater profile for use in slope-stability programs that require a 2-D cross section of a slope. Because the field tests and water-level predictions covered in this article were based on these methods, a summary of the physical testing program employed by Crenshaw and Santi is included below.

Crenshaw and Santi (Crenshaw, 2003; Crenshaw and Santi, 2004) used three laboratory-scale physical tests and computer modeling to analyze various recharge scenarios that could be expected to occur in the field based on the hydraulic conductivity of the soil composing a slide mass. The tests showed that the groundwater profile varied primarily according to average hydraulic conductivity. The profiles (Figure 2) were grouped based on whether the groundwater profile diverged upward from the drain at its end $\left(\mathrm{L}_{100}\right)$, or at some location along the drain corresponding to a percentage of its total length (Lc). Although Lc is important in Crenshaw and Santi's calculations to develop correction factors, these correction factors are not applicable for the conditions tested in this project, so Lc is not used except as reference to the location of groundwater divergences from the drains.

Crenshaw and Santi's three laboratory-scale tests varied the source of the recharge and the recharge rate. The first test simulated a rainfall event by allowing recharge from above and behind the drain system. The surface of the soil was pre-saturated, and steady state was established, denoted by constant heads in the test piezometers. Initial water-profile measurements were recorded, after which the water source was turned off. Measurements of the piezometric heads and flow rates were then recorded during drawdown. Drawdown was 


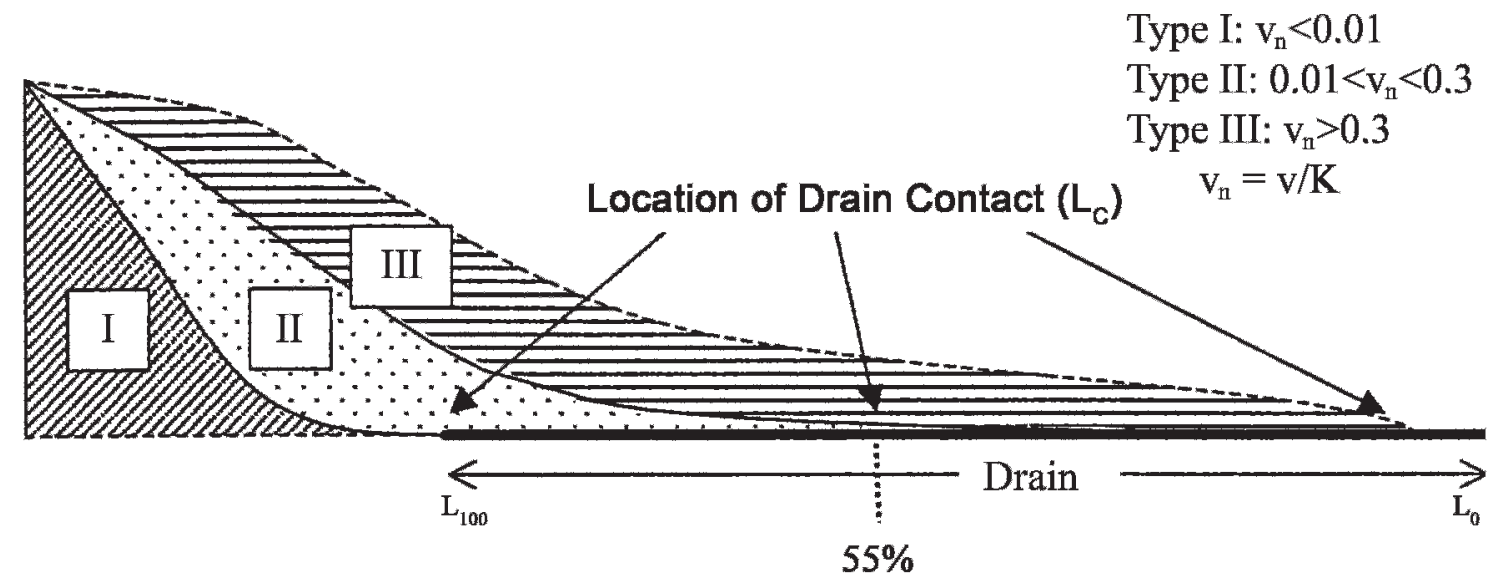

Figure 2. Groundwater profile classifications for horizontal drains, showing the location of drain contact, Lc (modified from Crenshaw, 2003).

sustained for about 1 hour for sand soils and 360 hours for clays and silts. The second test simulated a variable groundwater recharge source by allowing recharge only from behind the drain system. This was accomplished by the addition of a reservoir near the water-entry source in the test container. After steady state was established, in the same manner as the first test, the water source was turned off and measurements of the piezometric heads were recorded during drawdown to compare the changing groundwater profiles with the short-term changes in recharge rate. Drawdown was sustained for about 1 hour for sand soils and 96 hours for clays and silts. This simulation represented periodic high-precipitation events, spring snow thaws, or recharge due to agricultural irrigation. The third test simulated recharge from a constant groundwater source by allowing water to enter through a constant-head reservoir behind the drain system. To keep the recharge rate from varying, the test was performed in a sand soil so that the hydraulic conductivity would be high enough to keep the water from ponding in the test container. Once steady state was established, denoted by a constant volumetric flow from the drain, piezometric heads and the discharge flow rates from the drains were recorded. Because this third test was specifically for groundwater profiles under constant recharge, no drawdown measurements were recorded. Similar tests were repeated in the field, as described in the next section, in an effort to confirm the findings of the original work at a larger and more realistic scale.

\section{METHODS}

\section{Description of Test Site}

The test site consists of a $30 \times 12 \mathrm{ft}(9.1 \times 3.7 \mathrm{~m})$ concrete slab, which roughly approximates the bedrock surface typical of Quaternary-aged residual slopes in the area, constructed on a hill side at a 2H:1V (2 horizontal : 1 vertical) slope. In order to simulate the effects of excess infiltrated precipitation and groundwater seepage, the concrete slab was outfitted with both surficial and sub-surface infiltration systems. Five parallel, 1-in. (25.4-mm) diameter, perforated polyvinyl chloride (PVC) pipes were laid into troughs mechanically chipped into the concrete. Non-perforated PVC was used to extend the pipes to the top of the slope, where a junction box was used to accommodate a separate valve for each pipe. A main infiltration line providing water to the pipes was outfitted with a water meter to provide flow data during testing (Collins, 2006). The main infiltration line was also outfitted with a connection for a hose to provide surface soaking and infiltration. Soil compacted on top of the slab simulates residual soil developed on top of the bedrock.

\section{Test Slope Design}

The constructed soil slopes enabled water-level measurements to be taken both between and along drains in a hillside. Thus, in addition to two subhorizontal wick drains, rolled and tied with electrical ties to simulate drain pipes and spaced $8 \mathrm{ft}(2.4 \mathrm{~m})$ apart, the slopes included 50 piezometers (Figure 3 ). Three rows of 12 piezometers, spaced laterally at $1 \mathrm{ft}$ $(0.3 \mathrm{~m})$ intervals, were located $5 \mathrm{ft}(1.5 \mathrm{~m}), 10 \mathrm{ft}$ $(3.0 \mathrm{~m})$, and $20 \mathrm{ft}(6.1 \mathrm{~m})$ from the top of the slopes to measure groundwater profiles between drains at different intervals in the slopes. Additional piezometers were placed at $2 \mathrm{ft}(0.6 \mathrm{~m})$ intervals along the drains; four between the second and third lateral rows and three after the third lateral row. These additional piezometers enabled monitoring of the groundwater zone paralleling each side of each drain, where the 


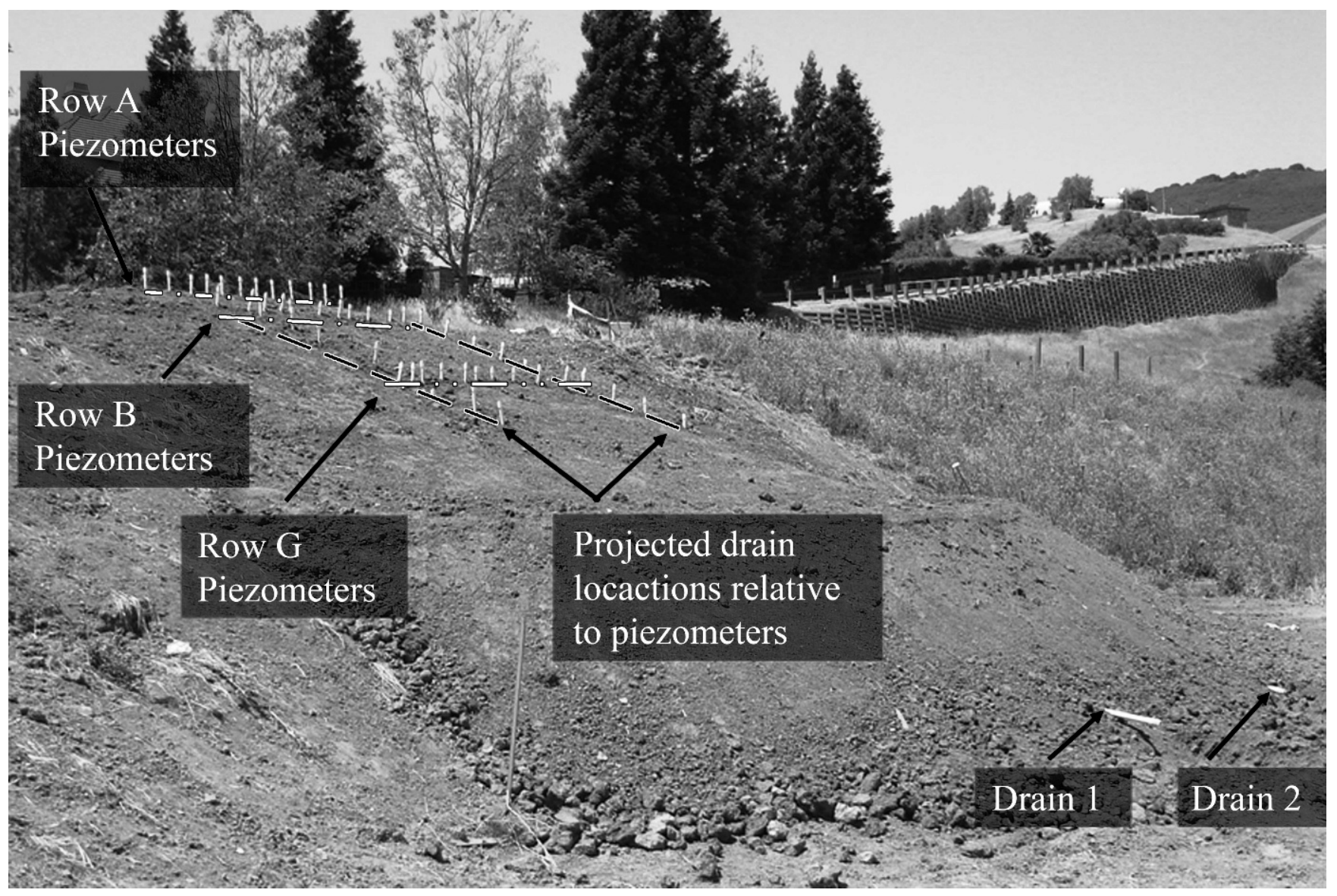

Figure 3. CL slope showing piezometers and drains. Piezometers were labeled by row letter and number from the left side of the photo to the right. For example, piezometers A1 to A12, located at the top of the slope. Drain 1 follows piezometers B2 through J1. Drain 2 follows piezometers B11 through $\mathrm{J} 2$.

characteristic groundwater surface was expected to diverge from the level of the drains. The end of each piezometer was capped by wire mesh, as used for window screening, and approximately $1 \mathrm{in.}(25.4 \mathrm{~mm})$ of sand was placed in each piezometer hole preceding placement of the piezometers. This configuration allowed some degree of physical filtering of the suspended-solids content of the slope water to prevent clogging of the piezometers. In addition, the piezometers were marked with a row letter and number for data collection purposes.

A toe berm, or key, was constructed at the base of the slopes to improve overall slope stability during testing. The key measured $16 \mathrm{ft}(4.9 \mathrm{~m})$ wide at the base, $2 \mathrm{ft}(0.6 \mathrm{~m})$ wide at the top, and $6 \mathrm{ft}(1.8 \mathrm{~m})$ high, with sides inclining approximately at a $3 / 4 \mathrm{H}: 1 \mathrm{~V}$ slope. The soil slopes inclined from the top of the key to the top of the concrete between $1 / 4 \mathrm{H}: 1 \mathrm{~V}$ and $1 / 3 \mathrm{H}: 1 \mathrm{~V}$.

To constrain the draining effects to the interior of the slopes and out of the key and to facilitate accurate measurement of drain drawdown of the groundwater surface, the wick drains were designed to be encased within an impermeable PVC pipe for approximately $16 \mathrm{ft}(4.9 \mathrm{~m})$ through the key to a discharge point near the base of the slope. The drain outlets were capped with female adaptors and threaded caps so that flow through the drains could be restricted when saturating the slopes. The wick drains were also designed to be embedded in several feet of soil, but inclined at no more than 25 degrees from the horizontal; generally, 25 degrees is the maximum angle of installation for horizontal drains (Cornforth, 2005), because higher drain inclinations will result in a decrease in the potential groundwater drawdown.

\section{Testing Program}

Initially, two main tests were planned for each of two soil slopes, CL and SC, natural soils obtained from native borrow sites. These soils were classified according to the Unified Soil Classification System using Atterberg Limits and grain size analysis testing. The first test was designed to allow recharge to initiate from only the top pipe in the slope. The second test was designed to allow recharge from both 
the top pipe in the slope and from a sprinkler above the slope to simulate recharge from a single, worstcase, sustained rainfall event. In addition, three different recharge rates were tentatively planned for each test, depending on the results collected from the initial recharge rates used.

In general, for the first set of tests, the drains were initially capped during slope saturation. The slopes were saturated using all five recharge pipes, but not all at once or continuously. The piezometric head was allowed to rise approximately $3.5 \mathrm{ft}(1.1 \mathrm{~m})$ and $4 \mathrm{ft}(1.2 \mathrm{~m})$ above the concrete and about $1.5 \mathrm{ft}(0.5 \mathrm{~m})$ and $2 \mathrm{ft}(0.6 \mathrm{~m})$ above the level of the drains in the CL slope and the SC slope, respectively. These heads were verified by lowering the tip of an electronic water-level indicator into the piezometers on the slope. After the slopes became saturated, the drains were uncapped and recharge continued from one or more of the top three pipes, depending on seepage patterns, so that the water was not allowed to seep up to and over the surface of the slope. The total rate of inflow was monitored and compared to the outflows of the two drains, which were measured with a bucket and a stopwatch. Steady state (defined as inflow $=$ outflow with relatively constant heads in the slope) was established in the CL slope at approximately $0.013 \mathrm{gal} / \mathrm{min} \quad\left(0.82 \mathrm{~cm}^{3} / \mathrm{s}\right)$. Steady state was established so that drawdown could be initiated with the maximum head, between drains, for the recharge rate used. The time to reach steady state also allowed the slope-mass water to take on its preferred shape relative to the location of the drains. The water source was then turned off, and the changes in the draining groundwater profile were recorded over periodic increments using an electronic water-level indicator. For the CL soil, drawdown was measured at 2, 6, 14, 30, 54, and 102 hours after the water source was turned off.

For the SC soil, the slope was initially saturated and an attempt to reach steady state was made. Steady state was not reached due to severe seepage issues. The slope was saturated again the following day, but because this second attempt to reach steady state also failed, drawdown was initiated regardless. Total drain outflow before the water source was shut off was approximately $0.42 \mathrm{gal} / \mathrm{min}\left(26.3 \mathrm{~cm}^{3} / \mathrm{s}\right)$. Drawdown water levels in the SC slope were measured at 1, 3, 7, and 15 hours after the water source was turned off.

The project schedule originally allowed for a week of construction on the CL slope and approximately 2 weeks of testing before a scheduled week-long hiatus in the program. As construction took twice as long as anticipated, the testing for the CL slope started with a preliminary saturation phase to gage how well the rest of the testing would proceed. Water-level data were collected for this preliminary saturation phase although there was not enough time for a full test. A full test was performed after the hiatus.

The second test was not performed for either slope because of seepage issues at even very low recharge rates (less than $0.015 \mathrm{gal} / \mathrm{min}\left[0.95 \mathrm{~cm}^{3} / \mathrm{s}\right]$ for the $\mathrm{CL}$ slope, and less than $0.10 \mathrm{gal} / \mathrm{min}\left[6.3 \mathrm{~cm}^{3} / \mathrm{s}\right]$ for the SC slope). With seepage issuing from the surface of the slopes, the infiltration from surface sprinklers would have been indeterminate, so this phase of the experiment was eliminated. The surficial seepage at such low recharge rates also made it impossible to allow for testing using significantly higher recharge rates.

Total testing time for the CL soil, including preliminary saturation (one full test) and an attempt to reach steady state at a recharge rate greater than that used for the first test, was approximately 14 days. Total testing time for the SC soil, including slope saturation and both attempts to reach steady state, was about 4 days.

\section{Calculated vs. Actual Piezometric Heads}

Equations established by Crenshaw and Santi (Crenshaw, 2003; Crenshaw and Santi, 2004) were used to calculate piezometric heads for both the CL and SC soil slopes. These calculated heads are taken from the location of drain contact (Figure 4) and represent an average maximum head $\left(\mathrm{H}_{\max }\right)$ and an overall average head $\left(\mathrm{H}_{\text {avg }}\right)$ midway between the drains. Thus the calculated heads are averages for the whole drain field. The equations used for the calculations are as follows.

$$
\mathrm{H}_{\max }=\left(\sqrt{\frac{\mathrm{v}}{\mathrm{K}}} \sqrt{\frac{\mathrm{S}^{2}}{4}-\mathrm{x}^{2}}\right)-\mathrm{d}
$$

Where $\mathrm{H}_{\max }=$ piezometric head above the drains and at the midpoint between two drains, $\mathrm{x}=$ horizontal distance from the midpoint of two drains, $(\mathrm{x}=0$ for $\left.\mathrm{H}_{\max }\right), \mathrm{K}=$ hydraulic conductivity, $\mathrm{S}=$ average horizontal spacing between drains, $\mathrm{d}=$ equivalent depth to low-permeability layer below the drains (Eq. 3), and $v=$ recharge rate (Eq. 4).

$$
\mathrm{H}_{\text {avg estimate }}=\left(\pi \frac{\mathrm{S}}{8} \sqrt{\frac{\mathrm{v}}{\mathrm{K}}}\right)-\mathrm{d}
$$

Where $\mathrm{H}_{\text {avg estimate }}=$ average piezometric head above the drains in a drained slope, $\mathrm{K}=$ hydraulic conductivity, $\mathrm{S}=$ average horizontal spacing between drains, $\mathrm{d}=$ equivalent depth to low-permeability 
a.) Oblique View

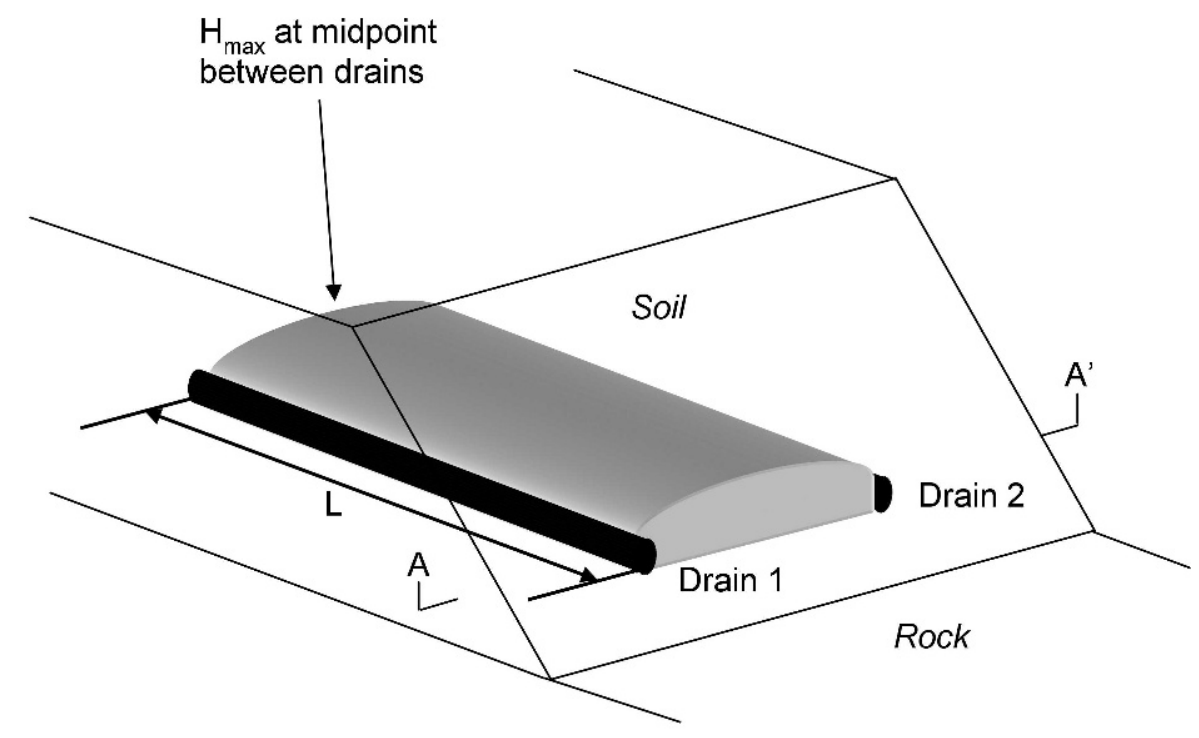

b.) Section View

Soil

Drain $1 \quad$ Drain 2

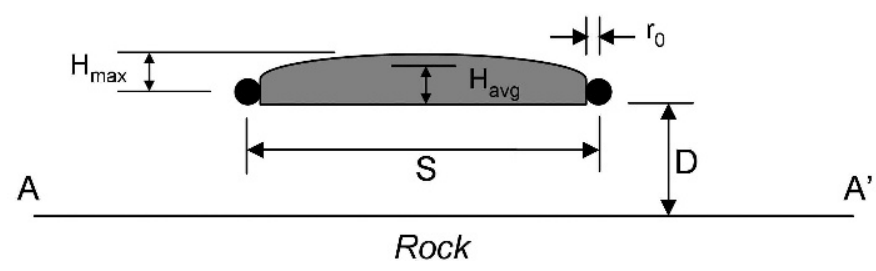

Figure 4. Schematic drained slope, showing parameters to be measured for calculations.

layer below the drains (Eq. 3), and $v=$ recharge rate (Eq. 4).

$$
\mathrm{d}=\frac{\mathrm{D}}{\left(1+\frac{8 \mathrm{D}}{\pi \mathrm{S}} \ln \left(\frac{\mathrm{D}}{\pi \mathrm{r}_{0}}\right)\right)}
$$

Where $\mathrm{d}=$ equivalent depth to low-permeability layer beneath the drainage field, $\mathrm{D}=$ field, or actual, depth to low-permeability layer beneath the drainage field, $\mathrm{S}=$ average horizontal spacing between drains, and $\mathrm{r}_{0}$ $=$ drain radius.

$$
v=\frac{\mathrm{Q}}{\mathrm{LS}} \text { or } v=\frac{\mathrm{Q}}{\mathrm{A}}
$$

Where $v=$ recharge rate, $\mathrm{Q}=$ discharge flow from a drain, $\mathrm{L}=$ average drain length in the drainage field, $\mathrm{S}=$ average horizontal spacing between drains, and A $=$ drainage area $(\mathrm{L} \times \mathrm{S})$.

The input parameters used in these equations are shown in Table 1. Parameters were either based on site geometry $(\mathrm{S}, \mathrm{D}, \mathrm{L})$, measured during testing $\left(\mathrm{r}_{0}\right.$,
Q), or estimated based on laboratory data (K). It should be noted that a slight modification to Crenshaw and Santi's method was used for calculating the recharge rate, $v$. Crenshaw and Santi's method uses the flow issuing from a single drain, $Q$, to calculate the recharge rate, $v$, over the drainage area of one drain (length of the drain multiplied by the drain spacing). Discharges from the two drains at the test site were added to get a total discharge. This total discharge was used in conjunction with the total area being drained to calculate recharge rate. This modification was justified by the fact that recharge to the soil was coming directly into the drain field between the two drains and not from outside the area between drains. Thus, instead of each drain draining an expected area of $\mathrm{L} \times \mathrm{S}$, each drain at the site was draining half of $\mathrm{L} \times \mathrm{S}$. Instead of halving the drainage area in the calculation of recharge rate, $v$, the total flow from both drains was used. This modification should not be necessary for general use of Crenshaw and Santi's method in more extensive drain fields. 
Table 1. Input Parameters Used To Calculate Crenshaw and Santi Piezometric Heads ( $1 \mathrm{ft}=0.3 \mathrm{~m}$ ).

\begin{tabular}{|c|c|c|c|c|}
\hline Slope Soil Type and Test Phase & $\begin{array}{c}\text { CL, Steady } \\
\text { State }\end{array}$ & $\begin{array}{l}\text { CL, } 6 \text { Hours } \\
\text { Drawdown }\end{array}$ & $\begin{array}{l}\text { SC, } 1 \text { Hour } \\
\text { Drawdown }\end{array}$ & $\begin{array}{c}\text { SC, } 3 \text { Hours } \\
\text { Drawdown }\end{array}$ \\
\hline Radius of drain, $\mathrm{r}_{0}(\mathrm{ft})$ & 0.042 & 0.042 & 0.042 & 0.042 \\
\hline Field depth to low-permeability layer, D (ft) & 1.87 & 1.87 & 1.78 & 1.78 \\
\hline Equivalent depth to low-permeability layer, d (ft) & 0.72 & 0.72 & 0.72 & 0.72 \\
\hline Flow from drains, $\mathrm{Q}\left(\mathrm{ft}^{3} / \mathrm{s}\right)$ & $2.90 \mathrm{E}-05$ & 2.23E-05 & 3.34E-04 & $1.67 \mathrm{E}-04$ \\
\hline Drain spacing, $\mathrm{S}(\mathrm{ft})$ & 8 & 8 & 8 & 8 \\
\hline Length of drains, L (ft) & 21.7 & 21.7 & 21.7 & 21.7 \\
\hline Drainage area, $\mathrm{A}\left(\mathrm{ft}^{2}\right)$ & 173.60 & 173.60 & 173.60 & 173.60 \\
\hline Recharge rate, $v(\mathrm{ft} / \mathrm{s})$ & $1.67 \mathrm{E}-07$ & $1.28 \mathrm{E}-07$ & $1.93 \mathrm{E}-06$ & $9.63 \mathrm{E}-07$ \\
\hline Hydraulic conductivity, $\mathrm{K}(\mathrm{ft} / \mathrm{s})$ & 4.27E-07 & 4.27E-07 & 4.27E-06 & 4.27E-06 \\
\hline
\end{tabular}

$\mathrm{CL}=$ sandy clay; $\mathrm{SC}=$ clayey sand.

It should also be noted that Crenshaw and Santi's method provides for a piezometric head correction factor to account for variable recharge rates in slopes with specific groundwater profile characteristics. In essence, the correction factor allows specific heads to be calculated along the profile near the back end of the drains, where the groundwater rises above the estimated $\mathrm{H}_{\mathrm{avg}}$. No correction factor was employed for the calculations carried out, mainly because, for this site geometry, the groundwater profiles do not rise at the back of the drain; instead the drains are dry along the end where they terminate in the slope. Thus, only average piezometric heads can currently be calculated for slopes with geometries similar to the field site.

After calculation of the average piezometric heads, a comparison was made to values measured from groundwater profiles along piezometer Row G. Row $G$ was chosen based on water-level data, which indicated that it was the location in the slope closest to the location of drain contact ( $\mathrm{Lc}$ ) and thus the location closest to the heads calculated using Crenshaw and Santi's method. The groundwater profiles used for the CL soil corresponded to steady state, or equilibrium, and drawdown at 6 hours, whereas the groundwater profiles used for the SC soil corresponded to 1 hour of drawdown, as steady state was not reached, and drawdown at 3 hours. In general, the water-level values measured in the eight piezometers located between the drains were used to estimate the average piezometric heads above the level of the drains. However, the CL steady state profile for piezometer Row $\mathrm{G}$ contained an anomalously high value near Drain 2. This value was not used as the maximum nor was it used in estimating the average piezometric head between drains.

\section{RESULTS}

The slope test results and piezometric head calculations are summarized below and in Figures 5 through 12. It should be noted that a few profiles have data points missing for some of the piezometers. No water was present in these piezometers, most likely as a result of clogging.

\section{Groundwater Profiles in the CL Slope}

Cross sections in the CL slope show a general rising of the groundwater between drains with some localized perturbations (Figure 5). In addition, the measured groundwater profiles were, in general, initially higher on the right side of the slope (right side of Figure 5), toward the front of the recharge pipes, and lower on the left (left side of Figure 5), near the end of the recharge pipes. This is especially apparent in Row $\mathrm{G}$ in Figure 5. As the water in the saturated slope was allowed to equilibrate over time, the discrepancy between the water levels decreased. Figure 5 also shows that localized perturbations present in the slope at equilibrium, after the hiatus in testing, exhibited greater relief than the perturbations present in the slope during initial saturation, particularly lower in the slope, near the vicinity of Row G. During drawdown, the water profiles between drains along Rows B and $\mathrm{G}$ changed shape slowly and by very little; the mid-point between drains stayed high compared to the areas around the drains as drawdown proceeded. As observed in cross sections along the drains (Figure 6), small pockets of perched water formed above Drains 1 and 2 during initial saturation, but equilibrated over time; the pockets flowed downhill and, because of the presence of the low permeability key, the slope-mass water started to back-up into the upper slope, creating large pockets of perched water near the front half of the drains. Along the drains, drawdown proceeded from back (near the slope crown) to front (near the slope toe).

\section{Groundwater Profiles in the SC Slope}

In general, cross sections between drains in the SC slope (Figure 7) show the same trends observed in the 

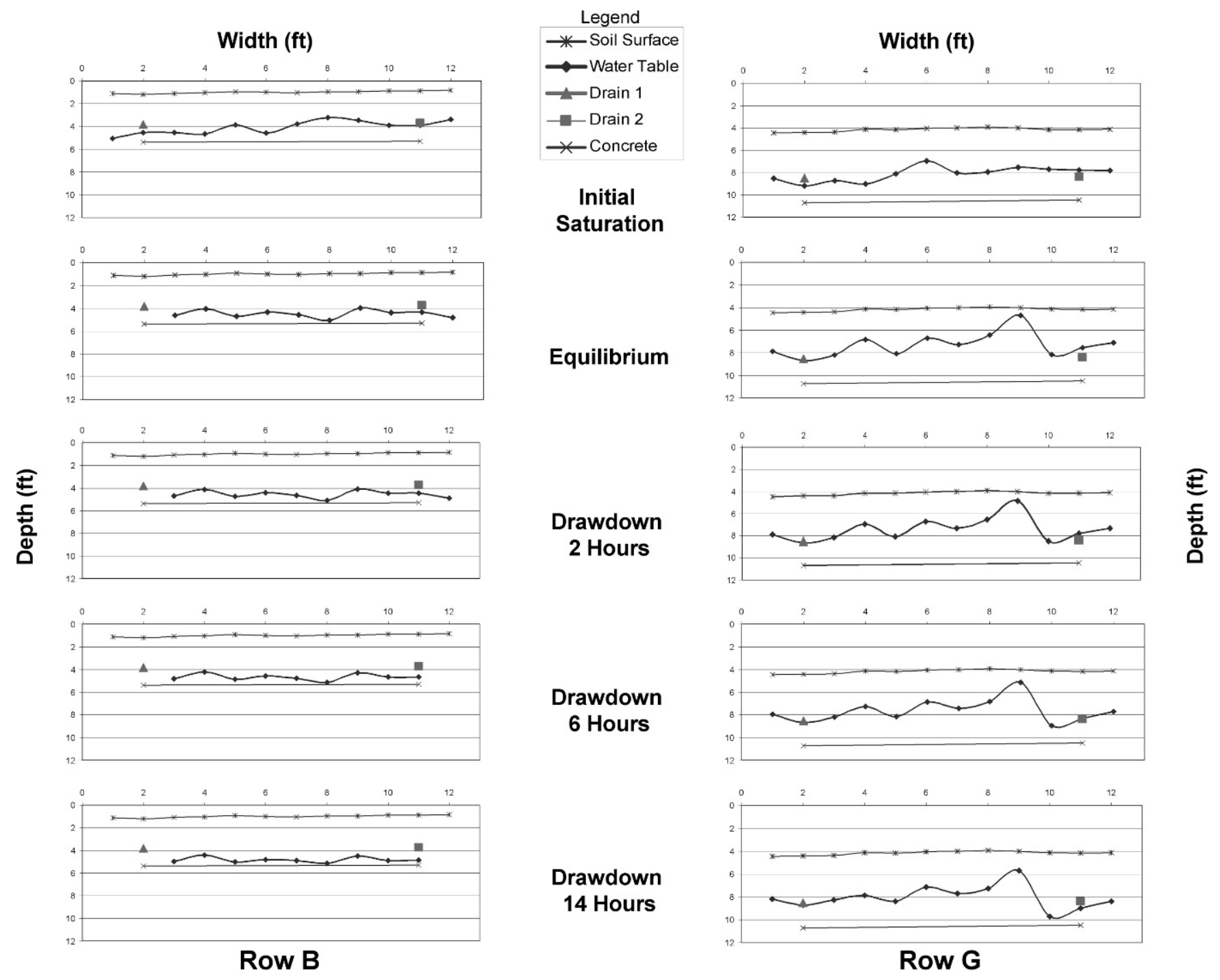

Drawdown
2 Hours

\section{Drawdown \\ 6 Hours}

\section{Drawdown 14 Hours}
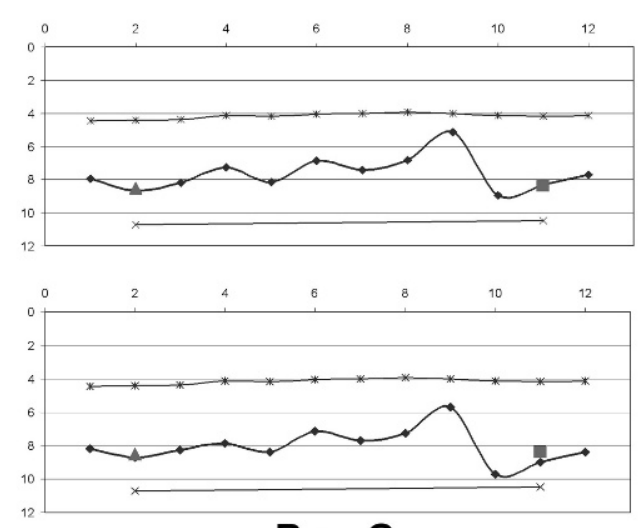

Row G

Figure 5. Groundwater profiles for Rows B and $G$ of the CL slope $(1 \mathrm{ft}=0.3 \mathrm{~m})$.

CL slope: a rising water surface between drains, higher water levels toward the front of the recharge pipes, exaggerated perturbations after a second saturation phase (this time mainly in Row B), faster drawdown in the vicinity of the drains, and slower drawdown near the mid-point between drains. Cross sections along drains in the SC slope were also, in general, similar to those for the CL slope (Figure 8). The perturbations along the drains increased in number and severity between the initial saturation of the slope and the second attempt to saturate the slope and bring it to steady state. In addition, large pockets of perched water similar to those along the drains in the CL slope also formed in the SC slope near the key boundary, although the pockets in the SC slope tended to be larger as a result of the higher permeability of the slope. Drawdown along the drains in the SC slope also proceeded from the back end of the water pocket toward the front of the drain, near the slope toe.
It should be noted that during the first attempt to reach steady state in the SC slope, a rise in the water levels in Row B was observed even though the drains were open and the recharge rate was very low. During the same period, Row $\mathrm{G}$ water levels receded. While saturating the slope the following day, Row B again exhibited unusually high water levels, especially compared to Row G (second saturation phase in Figure 7). These occurrences corresponded to severe surface seepage, which, as mentioned previously, proved especially difficult to control on the SC slope.

\section{Results for Calculated vs. Field-Measured Piezometric Heads}

Calculated heads and heads measured in Row G of the soil slopes show good agreement. Values calculated for the CL slope, shown in Table 2, vary by less 


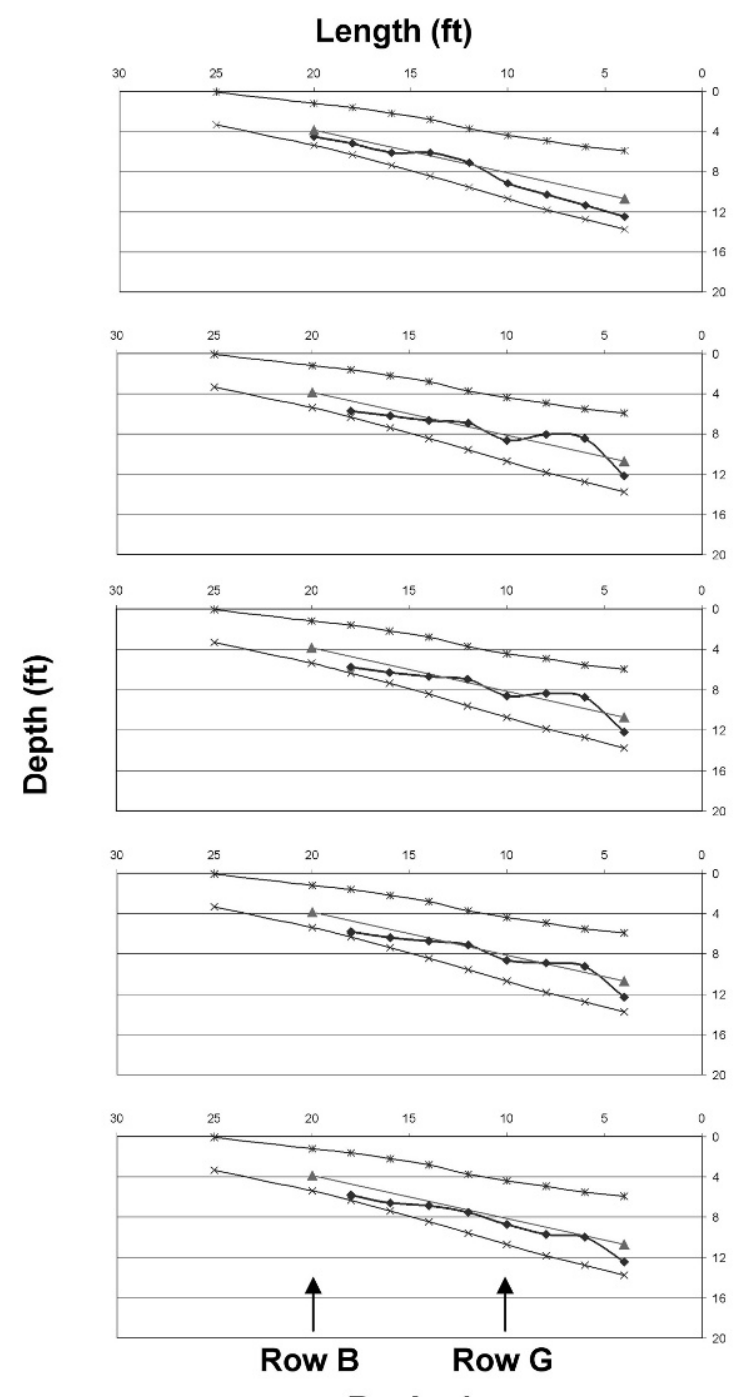

Drain 1

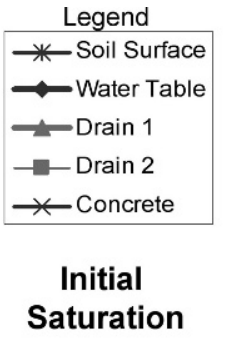

Equilibrium

Drawdown
2 Hours

Drawdown 14 Hours
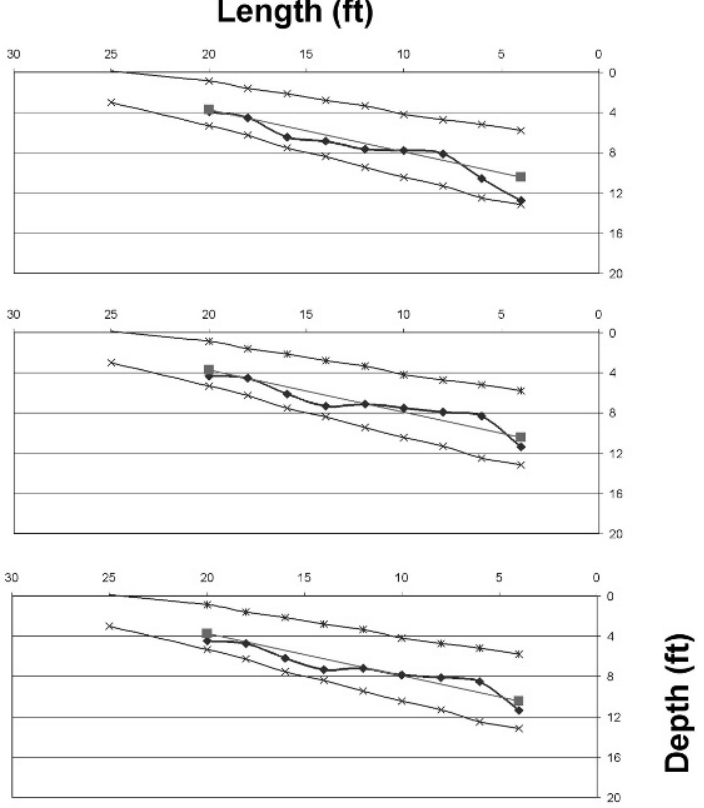

Figure 6. Groundwater profiles for Drains 1 and 2 of the CL slope $(1 \mathrm{ft}=0.3 \mathrm{~m})$.

than $0.3 \mathrm{ft}(0.09 \mathrm{~m})$ from heads measured in the field. Values calculated for the SC slope, shown in Table 3, vary by less than $0.35 \mathrm{ft}(0.11 \mathrm{~m})$ from heads measured in the field. A comparison of the calculated and field-measured results can also be seen in Figures 9 and 10 for the CL slope and Figures 11 and 12 for the SC slope.

\section{ANALYSIS AND DISCUSSION}

\section{Factors Influencing Water Levels}

Measured water levels appeared to exhibit the effects of factors beyond the release of pressure head through the wick drains. These factors may include some or all of the following:

- anisotropy/macropore flow
- effects of inconsistent compaction

- effects of shallow bedrock

- effects of vertical head distribution

- boundary effects of toe berm and sides

- effects of drain steepness

A more detailed description of how each of these factors may have influenced measured water levels is included below.

The deviations in the groundwater profiles were likely caused by several of the above factors. The slope soils were heterogeneous and therefore possessed some inherent anisotropy, as would the natural slopes they were intended to model. In addition, compaction around the piezometers was made difficult by their close proximity to each other, which compounded the anisotropy. Macropores appear to have developed both during the saturation phases of 


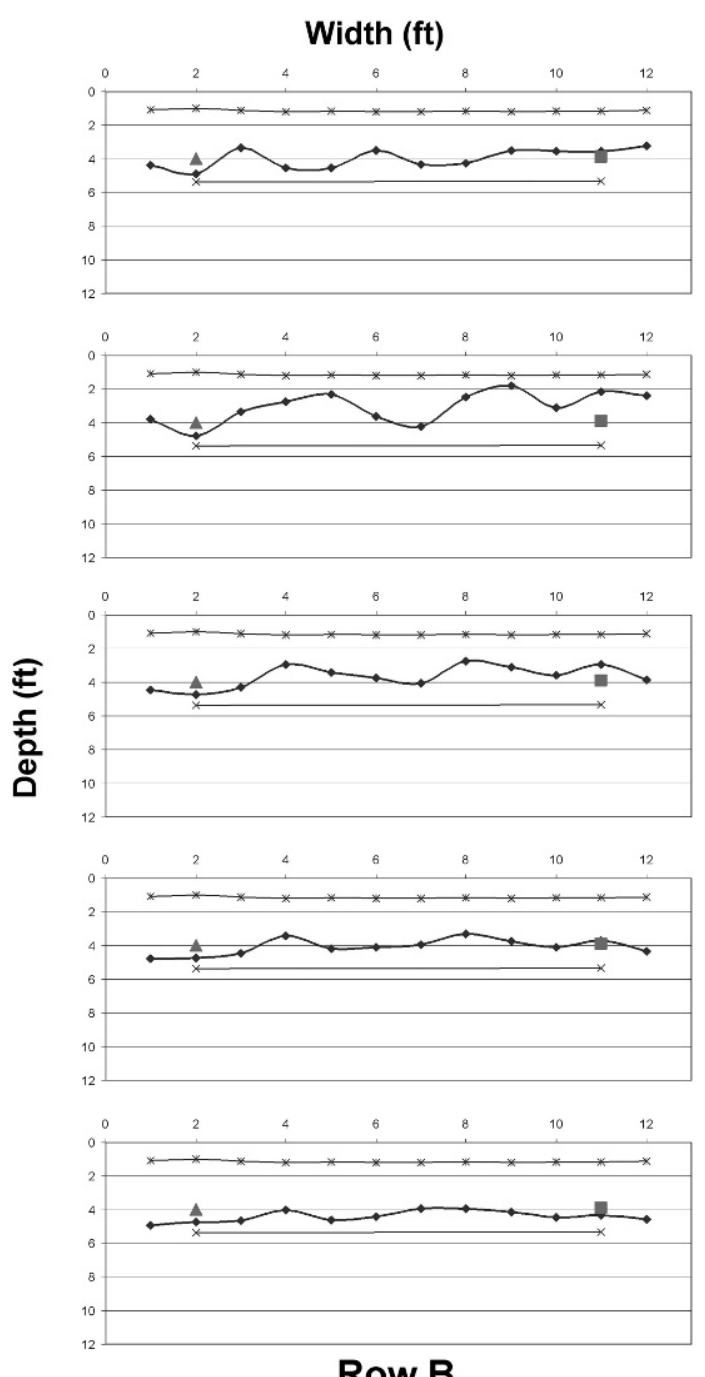

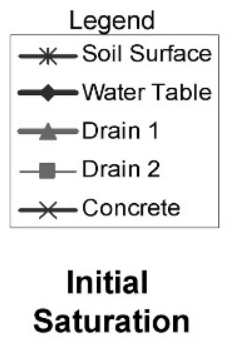
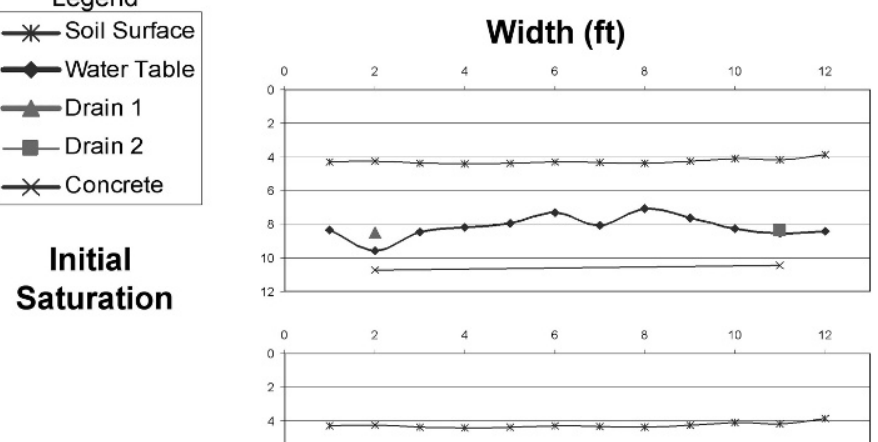

Second
Saturation
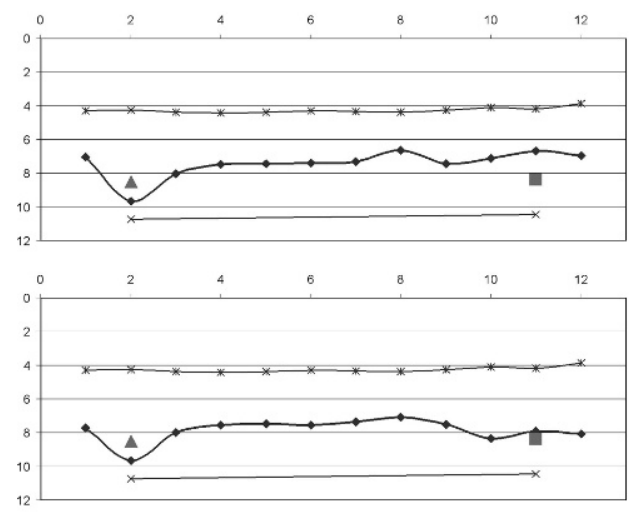

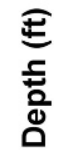

Drawdown

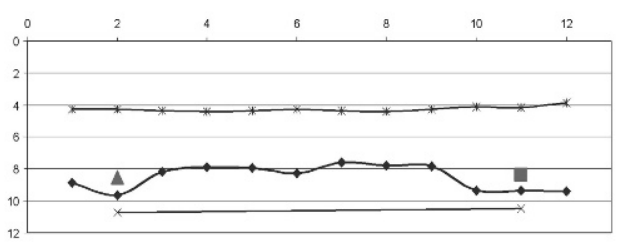

Drawdown
7 Hours

Drawdown
15 Hours

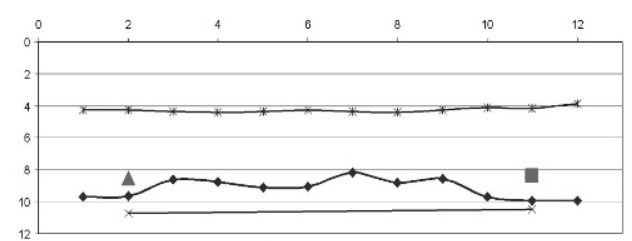

Row G

Figure 7. Groundwater profiles for Rows B and $\mathrm{G}$ of the $\mathrm{SC}$ slope $(1 \mathrm{ft}=0.3 \mathrm{~m})$.

testing and, especially in the case of the CL slope, during periods where the slope was allowed to dry and crack. The shallow bedrock and relatively thin soil in the slopes most likely contributed to the development of macropores and the ease with which the saturation front moved toward the surface, which, on many occasions, resulted in free-flow, spring-type, break-outs of surface seepage. Another possible contributing factor to the presence of local disturbances in the groundwater profiles is the effect of a variable vertical-head distribution in the slope. As the piezometer tips were not installed at the same depth, because of the presence of the concrete slope, the saturation front may not have spread equally to all piezometers. Whereas these factors may have decreased the accuracy of the results of this study, the same factors would also affect natural slopes, so these field tests are quite realistic.
The toe berm, or key, was built to be less permeable than the rest of the slope, resulting in a boundary effect that caused the water in both soil slopes to mound at the intersection of the key and the slope. The sides of the slope, however, were left in their natural state and appear to have had a slight influence on the groundwater profiles at the edges of the slopes only when the water levels in the slope dropped to the level of the drains. Finally, the steepness of the drains resulted in a portion of their length remaining dry even while they were draining effectively. Also, the steepness of the drains resulted in groundwater profiles along the drains that do not match those predicted by Crenshaw and Santi: the water profiles do not rise at the back of the slope, but instead tend to be dry at the back of the slope. Because Crenshaw and Santi's results were based on drains oriented close to the horizontal, it is expected that, had the drains at 

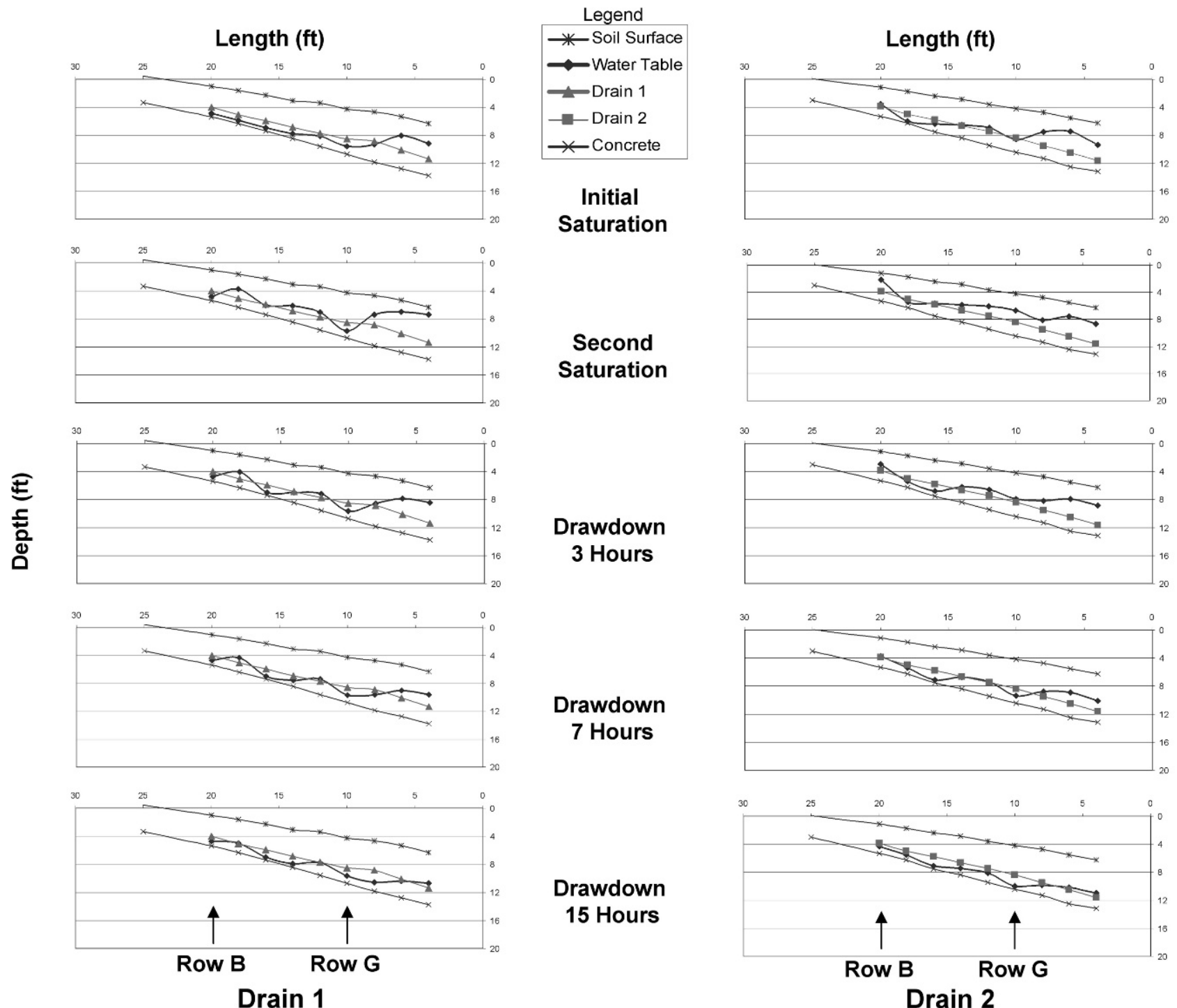

Saturation
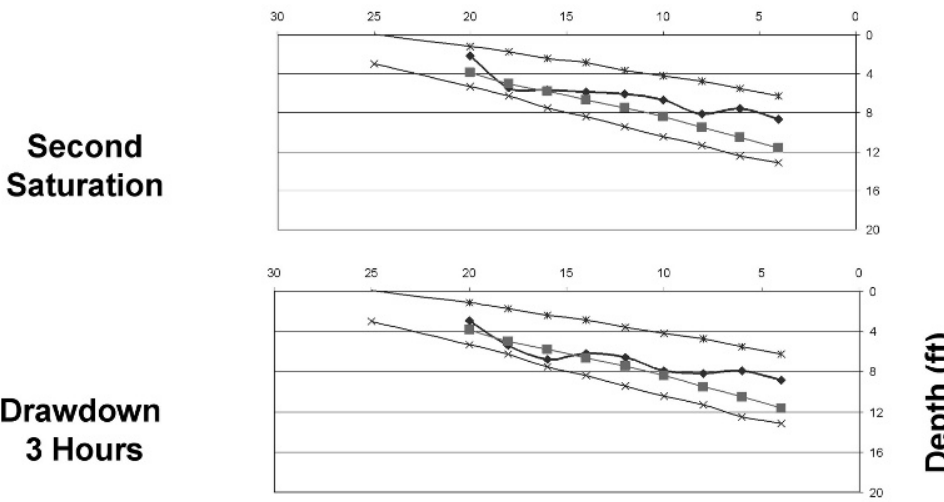

Drawdown
3 Hours

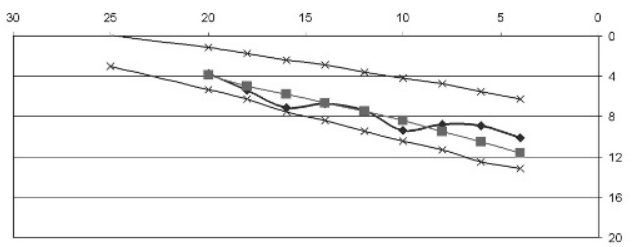

Drawdown
7 Hours

Drawdown 15 Hours

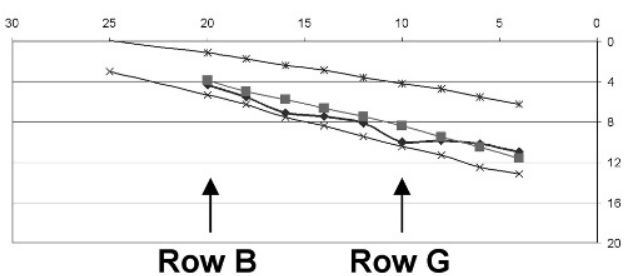

Drain 2

Figure 8. Groundwater profiles for Drains 1 and 2 of the SC slope $(1 \mathrm{ft}=0.3 \mathrm{~m})$.

the test site been inclined at a lower angle, the profiles would have been much closer in shape and orientation to those predicted by Crenshaw and Santi.

\section{Groundwater Profiles Between Drains}

In general, field testing was successful in verifying the corrugated shape of the groundwater surface between drains: the groundwater profiles between drains were mostly low near the drains and showed an increase between drains. Some local perturbations existed between drains in the majority of the profiles, for the reasons detailed above. These perturbations, which were not addressed in Crenshaw and Santi's work, do not appear to significantly affect the validity of their method, as will be discussed later.

Several of the profiles (Figures 5 and 7), especially during initial saturation and at the beginning of drawdown, showed groundwater profiles that were higher near the front of the recharge pipes (right side of the cross sections). As this was true for both the CL slope and the SC slope, the best explanation is that the water pressure in the recharge pipes was greatest where it entered the slope, near Drain 2, and that the water pressure in the pipes had dissipated greatly by the time it reached the vicinity of Drain 1.

As was noted in the results, unusually high water levels were seen in the vicinity of Row B in the SC slope. This mounding of the groundwater in the upper slope is interpreted as a result of low permeability zones in the soil near Row B. These low permeability zones may have been caused by native clays falling from the natural soil boundaries and mixing with the SC soil during construction. Another possible explanation for the presence of these zones is heavier compaction in the region directly below Row B. This 
Cook, Santi, Higgins, and Short

Table 2. Piezometric Heads in the CL Slope $(1 \mathrm{ft}=0.3 \mathrm{~m})$.

\begin{tabular}{lcccc}
\hline \hline & $\begin{array}{c}\text { Steady State } \\
\text { Calculated }\end{array}$ & $\begin{array}{c}\text { Steady State } \\
\text { Actual at Row G }\end{array}$ & $\begin{array}{c}\text { 6 Hours Drawdown } \\
\text { Calculated Hours Drawdown } \\
\text { Actual at Row G }\end{array}$ \\
\hline $\begin{array}{l}\text { Maximum piezometric head between drains, } \\
\mathrm{H}_{\text {max }}(\mathrm{ft})\end{array}$ & 1.78 & $2.05^{*}$ & 1.47 & $1.57^{*}$ \\
$\begin{array}{l}\text { Estimated average piezometric head between drains, } \\
\mathrm{H}_{\text {avg }}(\mathrm{ft})\end{array}$ & 1.24 & $1.08^{*}$ & 1.00 & $1.00^{*}$ \\
\hline
\end{tabular}

$\mathrm{CL}=$ sandy clay.

*Calculated without anomalous point.

area may have received heavier compaction than some of the other areas adjacent to piezometers because, due to the geometry of the test site (Figure 3), it was more accessible and not as tightly bounded by piezometers.

In the vicinity of Drain 1, the groundwater surface was often located below the level of the drain. This was also true for Drain 2, although only after the recharge pipes were closed and drawdown was initiated. This can be explained by both the steepness of the drains and the effects of seepage at the side boundaries. The steepness of the drains most likely plays a larger role, because the groundwater profiles generally rise slightly from below the drains toward the side boundaries (see Figure 7, drawdown at 3 hours). The side boundary effects appear to have had, in some cases, greater control over drainage after the water levels in the slopes had dropped to the level of the drains. This can be seen in Row B profiles in Figure 5 and for the Row $\mathrm{G}$ profile for drawdown at 15 hours in Figure 7. Had an additional row of piezometers been installed at a location 5 to $8 \mathrm{ft}$ (1.5 to $2.4 \mathrm{~m}$ ) lower in the slope from Row $\mathrm{G}$, closer to the front of the drains and the toe of the slope, slightly higher water levels near the vicinity of the drains would have been expected, as can be observed in groundwater profiles along the drains (Figures 6 and 8).

\section{Groundwater Profiles Along Drains}

Local perturbations along the drains are caused by the same factors as those between the drains. As shown in Figures 6 and 8, the groundwater profiles along the drains were high near the key boundary and the water tended to drain from the back of the drain (near the slope crown) to the front (near the slope toe). Crenshaw and Santi's results, as shown in Figure 2, indicate basically the opposite drain-flow results, with higher water levels near the back of the drain and a groundwater surface receding from near the slope toe toward the slope crown. This difference is explained by both the key boundary effects and the steepness of the drains; Crenshaw and Santi's tests did not include a key, and they used drains with orientations closer to the horizontal. Whereas this may at first appear to invalidate the use of the method with the presently-discussed field-test geometry, the accuracy of the results indicate that this actually is not the case.

\section{Piezometric Heads}

As shown in Tables 2 and 3 and Figures 9 through 12 , maximum and average piezometric heads calculated at or near steady state and during drawdown compare favorably with the predicted values and are within the same level of accuracy that Crenshaw and Santi (Crenshaw, 2003; Crenshaw and Santi, 2004) were able to show $( \pm 0.5 \mathrm{ft}[0.15 \mathrm{~m}])$. Row $\mathrm{G}$ was located only 10 lateral-ft $(3.0 \mathrm{~m})$ in-slope from the key, and therefore the groundwater surface elevation in this area may have been influenced by boundary effects. This could account for some of the variation between actual piezometric heads and calculated heads. Even with this possibility, the similarity

Table 3. Piezometric Heads in the SC Slope $(1 \mathrm{ft}=0.3 \mathrm{~m})$.

\begin{tabular}{lcccc}
\hline \hline & $\begin{array}{c}\text { 1 Hour Drawdown } \\
\text { Calculated }\end{array}$ & $\begin{array}{c}\text { 1 Hour Drawdown } \\
\text { Actual at Row G }\end{array}$ & $\begin{array}{c}\text { 3 Hours Drawdown } \\
\text { Calculated }\end{array}$ & $\begin{array}{c}3 \text { Hours Drawdown } \\
\text { Actual at Row G }\end{array}$ \\
\hline $\begin{array}{l}\text { Maximum piezometric head between } \\
\text { drains, } \mathrm{H}_{\text {max }}(\mathrm{ft})\end{array}$ & 1.97 & 1.73 & 1.18 & 1.39 \\
$\begin{array}{c}\text { Estimated average piezometric head } \\
\text { between drains, } \mathrm{H}_{\text {avg }}(\mathrm{ft})\end{array}$ & 1.39 & 1.05 & 0.77 & 0.85 \\
\hline
\end{tabular}

$\mathrm{SC}=$ clayey sand 


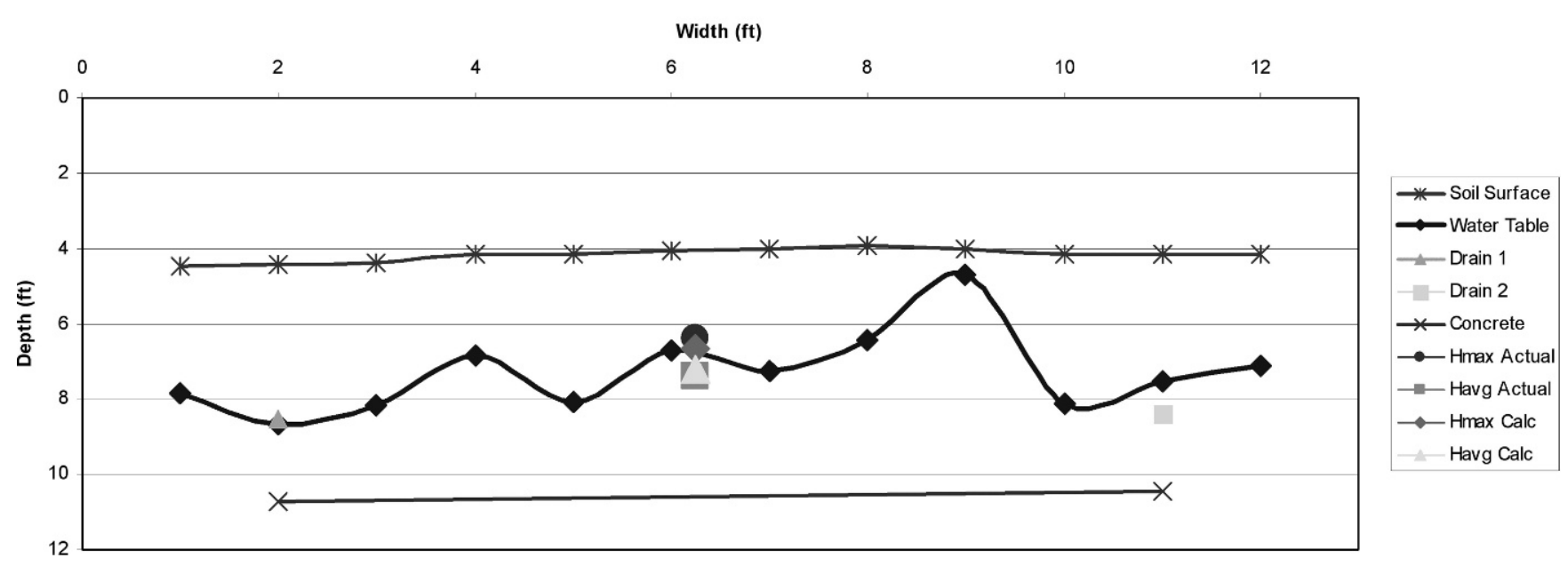

Figure 9. Comparison of calculated piezometric heads to actual piezometric heads at steady state in Row $\mathrm{G}$ of the CL slope (1 ft $=0.3 \mathrm{~m})$.

between actual and calculated heads for more than one type of soil and at different test phases implies that for the calculation of piezometric heads between short, high-angle sub-horizontal drains in shallow slides, Crenshaw and Santi's analytical solution can be reasonably employed.

\section{CONCLUSIONS}

Overall, the field-testing program confirmed the expected corrugated, vertical configuration of the groundwater profiles between horizontal drains, which was the original basis for Crenshaw and Santi's method. Also, the piezometric heads measured in the field compare favorably with predicted values, indicating the validity of the method for calculating piezometric heads between short, high-angle subhorizontal drains in shallow landslides. Further testing may be required before the method can be reasonably employed for sites with geometries that differ significantly from those discussed in this article.

Field-testing yielded additional information about the behavior of drained slopes that may be useful for future slope-stability projects. Groundwater profiles measured in the field were likely affected by as-yet unquantifiable parametric factors beyond the release of pressure head through the wick drains, which

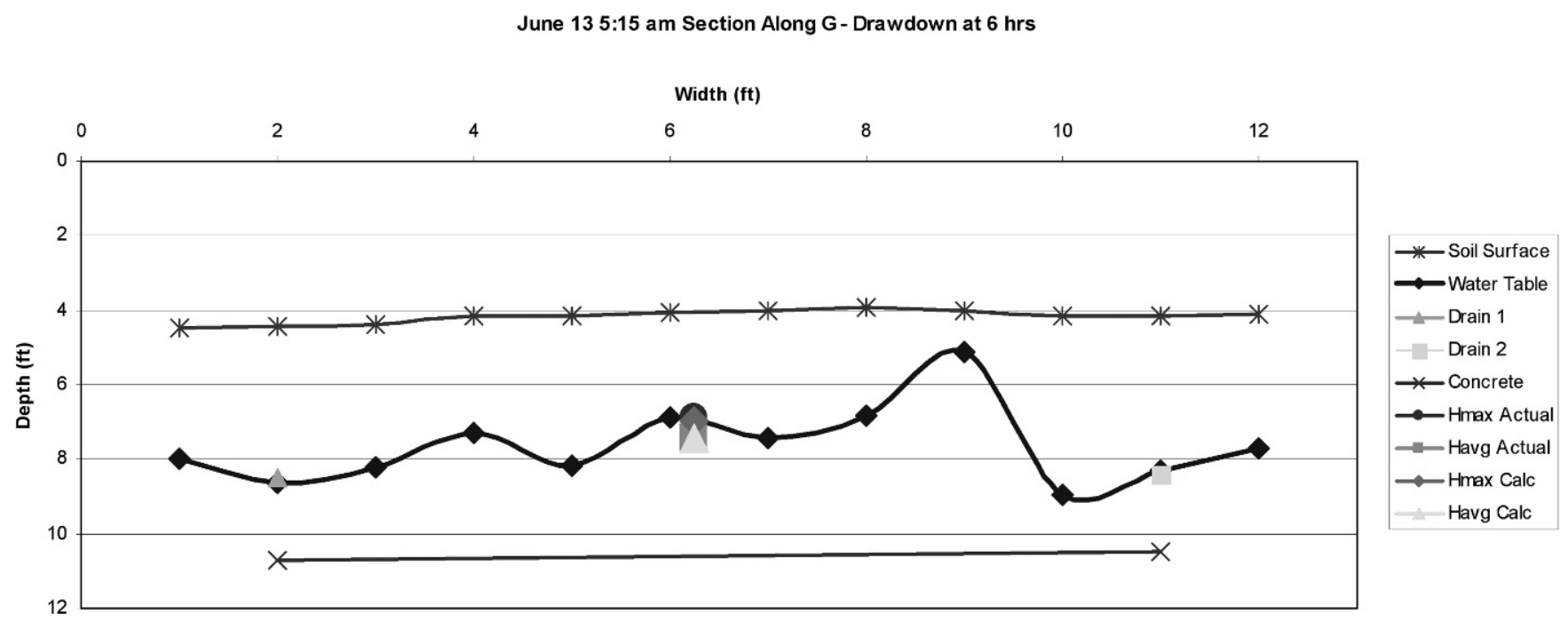

Figure 10. Comparison of calculated piezometric heads to actual piezometric heads at 6 hours drawdown in Row $\mathrm{G}$ of the $\mathrm{CL}$ slope $(1 \mathrm{ft}=$ $0.3 \mathrm{~m})$. 


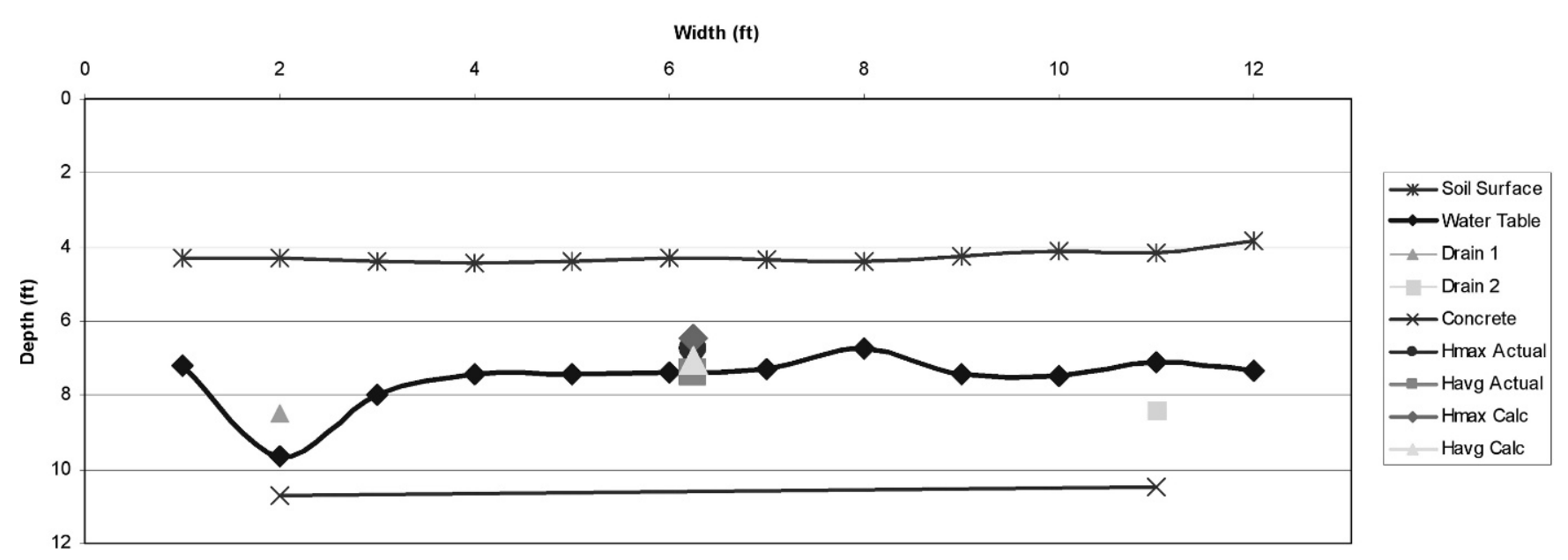

Figure 11. Comparison of calculated piezometric heads to actual piezometric heads at 1 hour drawdown in $\mathrm{Row} G$ of the $\mathrm{SC}$ slope $(1 \mathrm{ft}=$ $0.3 \mathrm{~m})$.

resulted in local perturbations between and along drains, as well as unexpected groundwater profiles along drains. The factors include:

- anisotropy/macropore flow

- effects of inconsistent compaction

- effects of shallow bedrock

- effects of vertical head distribution

- boundary effects of berm and sides

- effects of drain steepness

Field-testing also showed that sub-horizontal drains oriented at inclinations of 20-25 degrees are likely to be dry along portions of their length. In such situations, barring other outlets, the lower, front portions of the drains closest to the drain outlet will control drainage. Finally, low-permeability zones within the slope will create local mounding of the groundwater, on which drains may not have a significant influence.

\section{RECOMMENDATIONS}

Because the field-testing program verified Crenshaw and Santi's method for very specific conditions, the following recommendations for application of the method are only for use in locations that closely match these conditions, namely, shallow landslides with short, high-angle sub-horizontal drains.

To calculate an average piezometric head in a drained slope for slope-stability analyses, several

\section{July 1 9:00 pm Section Along G - Drawdown at 3 hrs}

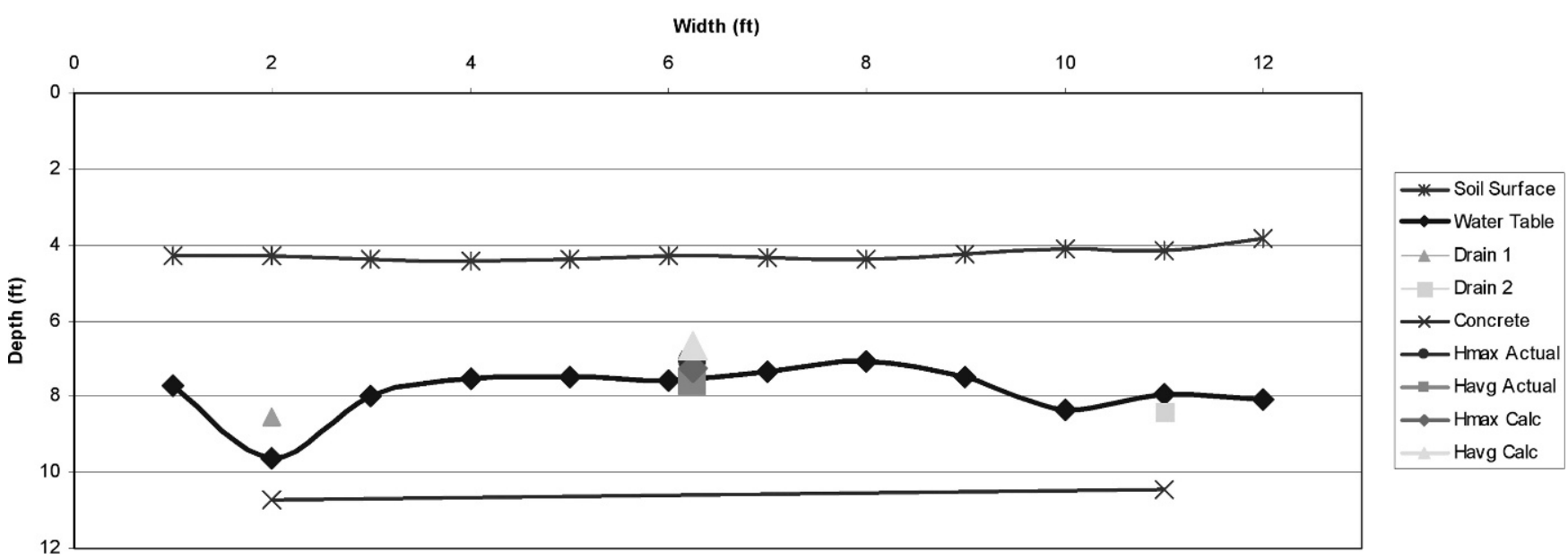

Figure 12. Comparison of calculated piezometric heads to actual piezometric heads at 3 hours drawdown in $\mathrm{Row} \mathrm{G}$ of the SC slope $(1 \mathrm{ft}=$ $0.3 \mathrm{~m})$. 
input parameters need to be determined. These parameters include the field depth to a low-permeability layer beneath the drains (D), the equivalent depth to the low-permeability layer beneath the drains (d), drain spacing (S), radius of the drains $\left(\mathrm{r}_{0}\right)$, average drain length (L), hydraulic conductivity $(\mathrm{K})$, recharge rate $(\mathrm{v})$, and discharge rate $(\mathrm{Q})$. These parameters may be established as follows.

- Estimate the field depth (D) to the closest lowpermeability layer beneath the level of the drains. This may be done through the use of drilling logs in the area of drain installation or from interpretation of regional geology or engineering geology maps. If the low-permeability layer is dipping at an angle, an average field depth may be obtained by averaging the depths at different cross-section intervals up the slope. The low-permeability layer must, by definition, be an underlying unit characterized by a hydraulic conductivity equal to one-tenth the hydraulic conductivity of the layer being drained (Luthin, 1966). This field depth value is used to calculate an equivalent depth value (d), which accounts for variances due to radial flow into the drains. For $\mathrm{D}>1 / 4 \mathrm{~S}$, the value $\mathrm{d}$ is constant (Prellwitz, 1978).

- Estimate the average drain spacing (S) in the drainage field. For uniform drain spacing, the average may be measured directly on a site map. For drains in a fan configuration or with varied spacing, refer to Crenshaw and Santi (2004) for an example calculation of the average spacing.

- Use the measured radius of the drains $\left(\mathrm{r}_{0}\right)$, the field depth (D) to the low-permeability layer beneath the drains, and the average drain spacing (S) to calculate the equivalent depth (d) to the lowpermeability layer using Equation 3.

- Calculate the average drain length (L) from a site map or from installation records.

- Estimate the hydraulic gradient $(\mathrm{K})$ of the slope material through lab testing, field testing, or with general values reported in pertinent literature.

- Estimate the recharge rate $(v)$ in one of two ways:

1) Use the average discharge rate from a drain $(Q)$, the average drain spacing (S), and the average length of the drains in the drainage field (L) to calculate the recharge rate (v) using Eq. 4. This requires direct measurement of discharge rates in a drainage field already containing drains or an estimate for an average discharge rate based on prior experience and/or records of flow rates from similar projects. A summation of the total discharge from all drains in a drain field divided by the total drainage area may also be used to calculate an average recharge rate.

2) Use normalized recharge rates $\left(v_{n}\right)$, where $v_{n}=v /$ $\mathrm{K}$, established by Crenshaw and Santi (Crenshaw, 2003; Crenshaw and Santi, 2004). Crenshaw and Santi found that normalized recharge rates vary between 0.01 and 0.3 for typical slopes; little to no lowering of the groundwater will occur below 0.01 , and normalized recharge rates above 0.3 are generally not expected to occur in the field. Normalized recharge rates for the field test site were somewhat higher than those indicated by Crenshaw and Santi, probably because of the steepness of the low-permeability layer and the method used for recharging the slope. Field values were between 0.3 and 0.4 for the CL slope and 0.2 and 0.45 for the SC slope. It is recommended that a range of recharge rates be estimated using a minimum normalized recharge rate of 0.01 and a maximum normalized recharge rate of 0.4 .

- Calculate average piezometric head $\left(\mathrm{H}_{\text {avg estimate }}\right)$ using Equation 2. This average head above the drains may be used as a conservative value in slopestability analyses as opposed to assuming the groundwater surface in a drained slope is located at the drain level. If a desired average water level has been estimated from a slope-stability analysis, the method may also be used in reverse to estimate an average spacing for short, high-angle subhorizontal drains in shallow hill-slopes.

\section{ACKNOWLEDGMENTS}

Funding for this project was provided by the U.S. Department of Education's Graduate Assistance in Areas of National Need (GAANN) program and by the Blackhawk Geologic Hazard Abatement District of Contra Costa County, California. Special thanks are extended to Ms. Elsi Thompson, whose field notetaking and graphics expertise are greatly appreciated.

\section{REFERENCES}

Collins, B. D., 2006, Summary of Phase 2 Plate Pile Testing at the Blackhawk GHAD Report: prepared for the Blackhawk Geologic Hazard Abatement District, Contra Costa County, CA, June 14, 2006, 40 p.

Cook, D. I.; SAnTi, P. M.; AND Higgins, J. D., in press, Horizontal landslide drain design: State-of-the-art and suggested improvements: Environmental Engineering Geoscience.

Connforth, D. H., 2005, Landslides in Practice: Investigation, Analysis, and Remedial/Preventative Options in Soils: John Wiley \& Sons, Inc., Hoboken, NJ, pp. 315327. 
Cook, Santi, Higgins, and Short

Crenshaw, B. A., 2003, Water Table Profiles in the Vicinity of Horizontal Drains: Unpublished M. Eng. Thesis, Department of Geology and Geological Engineering, Colorado School of Mines, $186 \mathrm{p}$.

Crenshaw, B. A. and SAnti, P. M., 2004, Water table profiles in the vicinity of horizontal drains: Environmental Engineering Geoscience, Vol. X, No. 3, pp. 191-201.

Luthin, J. N., 1966, Drainage Engineering: John Wiley \& Sons, Inc., New York, pp. 151-156.
Prellwitz, R. W., 1978, Analysis of parallel drains for highway cut-slope stabilization. In Humphrey, C. B. (Editor), Proceedings of the Sixteenth Annual Engineering Geology and Soils Engineering Symposium: Idaho Transportation Department, Division of Highways, Boise, ID, pp. 153-180.

Santi, P. M.; Crenshaw, B. A.; and Elifrits, C. D., 2003, Demonstration projects using wick drains to stabilize landslides: Environmental Engineering Geoscience, Vol. IX, No. 4, pp. 339-350. 